УДК 334.021

V.P. Popkov, A.M. Zargaryan, N.V. Zyabliskay

\section{THE MAIN DIRECTIONS OF INCREASING THE DEVELOPMENT EFFICIENCY OF ENTREPRENEURSHIP FROM THE EU- ROPEAN NORTH OF RUSSIA}

The article is devoted to the actual issues of entrepreneurship and government interaction efficiency increasing. In case of entrepreneurship sectors from the European North of Russia it is established the lack of institutional infrastructure, the weak entrepreneurship involvement to the public-private partnership. The main plan packages, which could increase the regional entrepreneurship development efficiency, are proposed.

Keywords: small and medium entrepreneurship, public-private partnership, institutional infrastructure, efficiency, interaction.

\author{
В.П. Попков ${ }^{1}$, А.М. Заргарян ${ }^{2}$, \\ Н.В. Зяблицкая ${ }^{3}$

\section{ОСНОВНЫЕ НАПРАВЛЕНИЯ ПОВЫШЕ- НИЯ ЭФФЕКТИВНОСТИ РАЗВИТИЯ ПРЕДПРИНИМАТЕЛЬСТВА ЕВРОПЕЙ- СКОГО СЕВЕРА РОССИИ}

Статья посвящена актуальным вопросам повышения эфффективности взаимодействия предпринимательских структур и государства. На примере отраслей предпринимательства Европейского Севера России установлена нехватка институциональной инфраструктуры, слабая вовлечённость субъектов предпринимательства к государственно-частному партнёрству. Предложен комплекс мероприятий, способных повысить эфффективность развития предпринимательского сектора региона.

Ключевые слова: малое и среднее предпринимательство, государственно-частное партнёрство, институциональная инфраструктура, эффрективность, взаимодействие.

DOI: 10.36807/2411-7269-2021-4-27-35-41

В современных условиях функционирования рыночной экономики система малого и среднего предпринимательства (далее - МСП) выполняет функцию самого важного звена в обеспечении экономического роста страны. Благодаря субъектам предпринимательства проходят апробацию новые сферы деятельности, создаются и развиваются новые технологии, обеспечивается так называемая диффузия инновации. Весомый вклад МСП также прослеживается в создании новых рабочих мест. Именно в данной сфрере реализуется предпринимательская инициатива граждан, отличающихся инновационным характером, способностью и желанием принятия предпринимательского риска ради достижения целей.

Вместе с тем, предпринимательские системы функционируют в условиях высоких рисков, которые оказывают негативное влияние на уровень развития МСП. Усиление степени влияния рыночных сил приводит к тому, что предпринимательские структуры признают фракт невозможности контроля всех факторов, оказывающих влияние на предпринимательский бизнес. Одновременно с этим современные рыночные отношения предъ-

\footnotetext{
1 Попков В.П., доктор экономических наук, профессор кафедры торгового дела и товароведения; профессор; Федеральное государственное бюджетное образовательное учреждение высшего образования "СанктПетербургский государственный экономический университет", г. Санкт-Петербург

Popkov V.P., Doctor of Economics, Professor of the Department of the Department of Trade and Commodity Science; professor; Federal State Budgetary Educational Institution of Higher Education "Saint-Petersburg State University of Economics", Saint-Petersburg

E-mail: Popkov.V.@unecon.ru

${ }^{2}$ Заргарян А.М., доцент кафедры экономики и управления, кандидат экономических наук; Череповецкий государственный университет, г. Череповец

Zargaryan A.M., Associate Professor of the Department of Economics and Management, PhD in Economics; Cherepovets State University, Cherepovets

E-mail: arshakz@inbox.ru

${ }^{3}$ Зяблицкая Н.В., заведующая кафедрой общеэкономических и специальных дисциплин, доктор экономических наук, профессор; Филиал Федерального государственного бюджетного образовательного учреждения высшего образования "Южно-Уральский государственный университет", г. Нижневартовск

Zyabliskay N.V., Head of the Department of General Economic and Special Disciplines, Doctor of Economics, Professor; Branch of the Federal State Budgetary Educational Institution of Higher Education "South Ural State University", Nizhnevartovsk

E-mail: comm@susu-nv.ru
} 
являют более высокие требования к качеству управления, усложняют отношения внутри предпринимательского сектора.

Это приводит к тому, что подавляющая часть предпринимательских структур в ходе своего развития не доходит до этапов рыночного созревания. Бизнес либо трансформирует свой вид, меняя целевые ориентиры, либо поглощается крупными участниками рынка. Поэтому сфрера МСП, являясь самой динамичной сферой, постоянно требует апробации новых идей.

В текущий момент уровень развития предпринимательства в России значительно отстаёт от других стран. Вклад предпринимательского сектора в ВВП страны оценивается на уровне $21 \%$, в то время как в Японии и Китае показатель составляет $60 \%$, во Франции - 56\%, США и Великобритании - 50\%.

Для установления причин слабого развития предпринимательского сектора проведено исследование приоритетных отраслей предпринимательства Европейского Севера России, которое выявило ключевые системные проблемы функционирования предпринимательских структур.

Выявленные проблемы имеют непосредственное отношение к противоречивым аспектам государственного регулирования и проблемам внутрифирменного управления.

Проблема 1. Низкая вовлечённость МСП к процессу государственно-частного партнёрства.

Государственно-частное партнёрство содержит ряд противоречий, не позволяющих обеспечить полное участие субъектов МСП в государственных программах. Данный механизм может быть реализован только по отношению к проектам, имеющим важное социально-экономическое значение для государства и потенциально высокую доходность для МСП. Проблема начинается тогда, когда государство определяет условия своего участия в подобных проектах, а также требования, предъявляемые к субъектам МСП. К наиболее значимым требованиям можно отнести:

- $\quad$ наличие опыта реализации проектов в смежных отраслях;

- наличие материально-технической базы, позволяющей выполнять наиболее значимые работы в рамках проекта;

- ограниченность государственного участия в проектах нефинансовыми инструментами, прямым образом не затрагивающими бюджет (льготные условия аренды земельных участков, налоговые льготы);

- обязанность бизнеса по созданию инфраструктурных элементов за свой счёт.

Очевидно, что далеко не каждый бизнес, функционирующий в секторе МСП, может удовлетворять заявленным требованиям. Кроме того, далеко не во всех проектах ГЧП возможен механизм обеспечения сиюминутной прибыльности частного бизнеса, что не соответствует приоритетным задачам субъектов МСП. Особенно в тех проектах, где с помощью механизма ГЧП государство обеспечивает своё минимальное участие в решении социально-экономических проблем.

На начало 2016 г. на территории России на разных стадиях разработки и реализации находилось 1285 проектов ГЧП. Основная часть проектов продолжает реализоваться в коммунальной и энергетической сферах (987 проектов), остальные - в социальной и транспортной сфрерах (298 проектов). Преимущественная часть таких проектов находится на предынвестиционной стадии подготовки (подготовка проекта, конкурс) [3].

Процесс рассмотрения проекта ГЧП состоит из трёх этапов. На первом этапе разработанный инициатором проект направляется на рассмотрение Публичным партнёром (актуален в случае разработки проекта частным партнёром). На втором этапе предложение о реализации проекта ГЧП рассматривается уже уполномоченным органом в целях оценки эфффективности проекта и определения его сравнительного преимущества. Третий этап состоит в принятии уполномоченным органом решения о реализации проекта. Сразу следует оговориться, что потенциальные участники ГЧП не подразделяются государством на разные типы в зависимости от размеров, опыта, уровня владения производственными силами (Рис. 1) [1], [6].

В первом приближении процедура рассмотрения проектов ГЧП представляется вполне простой, не требующей значительных усилий инициатора проекта. В обобщённом виде инициатор проекта может рассчитывать на своё безусловное участие в инициированном им проекте ГЧП в случае положительной оценки со стороны государства. Однако детальное рассмотрение процесса государственного отбора частных партнёров приводит к неоднозначным выводам. Для обоснования причин слабого участия представителей МСП в проектах ГЧП следует более подробно рассмотреть каждый из трёх этапов процесса оценки проектов и отбора участников ГЧП (Рис. 2) [2]. 


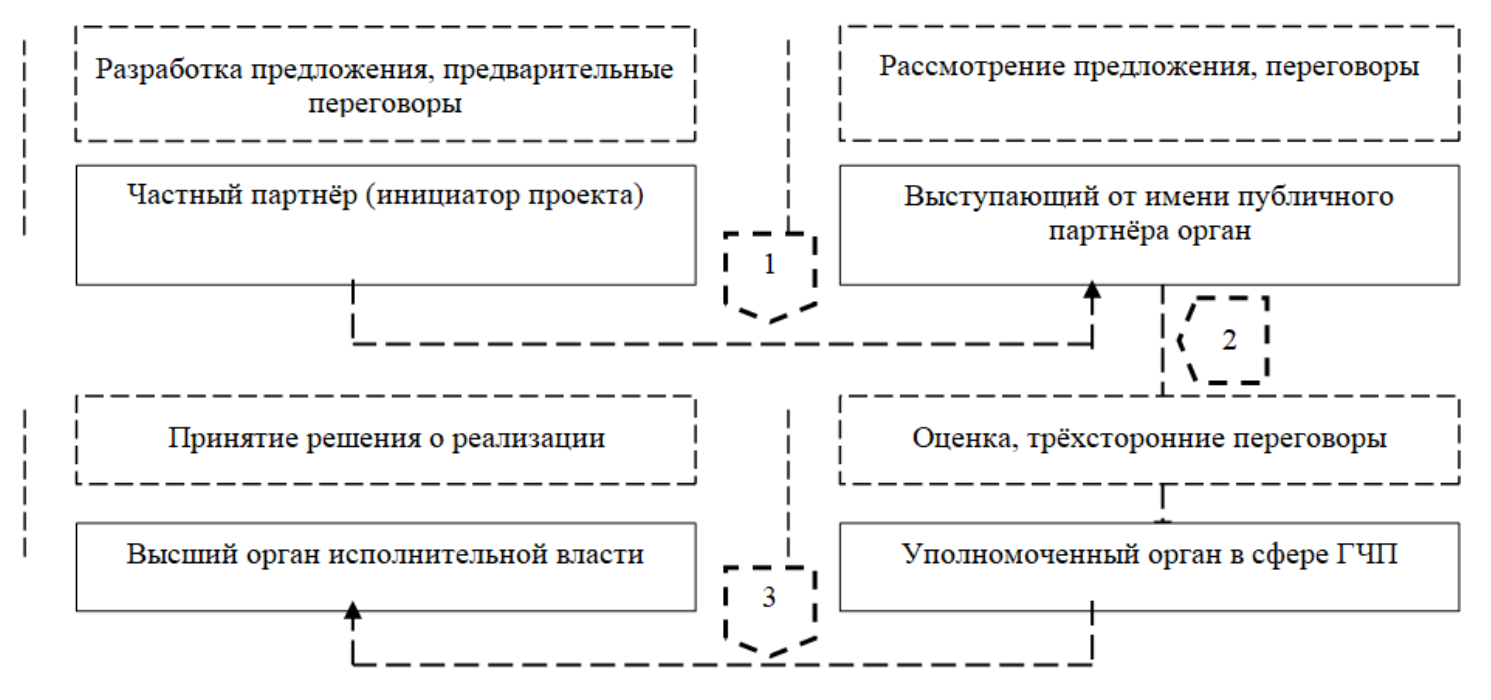

Рис. 1 - Этапы рассмотрения проекта ГЧП

На первом этапе Публичным партнёром направляется предложение инициатора проекта на рассмотрение Уполномоченным органом. Задача Уполномоченного органа состоит в оценке сравнительного преимущества предлагаемого проекта. В случае невозможности реализации проекта Публичный партнёр пользуется закрытым перечнем отказов. В случае положительного решения направляет предложение инициатора Уполномоченному органу на рассмотрение. Процедура рассмотрения предложения Публичным партнёром может занять до 90 дней.

На втором этапе рассмотрения частной инициативы осуществляется оценка эфффективности предлагаемого проекта ГЧП. В качестве основных критериев оценки используется фринансовый и социально-экономический эффект от реализации проекта. Сравнительное преимущество проекта ГЧП определяется Уполномоченным органом на основании соотношения чистых дисконтированных расходов бюджетных средств и объёма принимаемых Публичным партнёром обязательств в случае возникновения рисков реализации проекта. Процедура оценки эффективности потенциального проекта Уполномоченным органом занимает до 180 дней.

На третьем этапе рассмотрения частной инициативы Уполномоченный орган принимает решение о возможности или невозможности реализации проекта. В случае принятия положительного решения Уполномоченный орган публикует информацию о проекте на официальном сайте РФ о проведении торгов. Далее возможны два варианта развития событий. В случае отсутствия заявлений от третьих лиц о намерении участвовать в конкурсе Уполномоченный орган принимает решение о заключении ГЧП с инициатором проекта без проведения конкурса. В случае поступления заявлений о намерении третьих лиц участвовать в конкурсе Уполномоченный орган проводит ГЧПконкурс, который в общей сложности может занять до 180 дней.

Представленная совокупность этапов от момента инициирования проекта ГЧП частным партнёром до его заключения с государством может занимать более 12 месяцев. Кроме того, даже при условии положительного решения Уполномоченного органа, высокой оценки эффрективности проекта, инициатор проекта не может быть уверен в том, что проект ГЧП будет заключён с ним.

Таким образом, предложенная гипотеза относительно низкой степени участия представителей МСП в механизме ГЧП подтверждается отсутствием адаптированных для МСП проекта ГЧП, трудоёмкостью процесса инициирования предложений и участия в конкурсе ГЧП. 


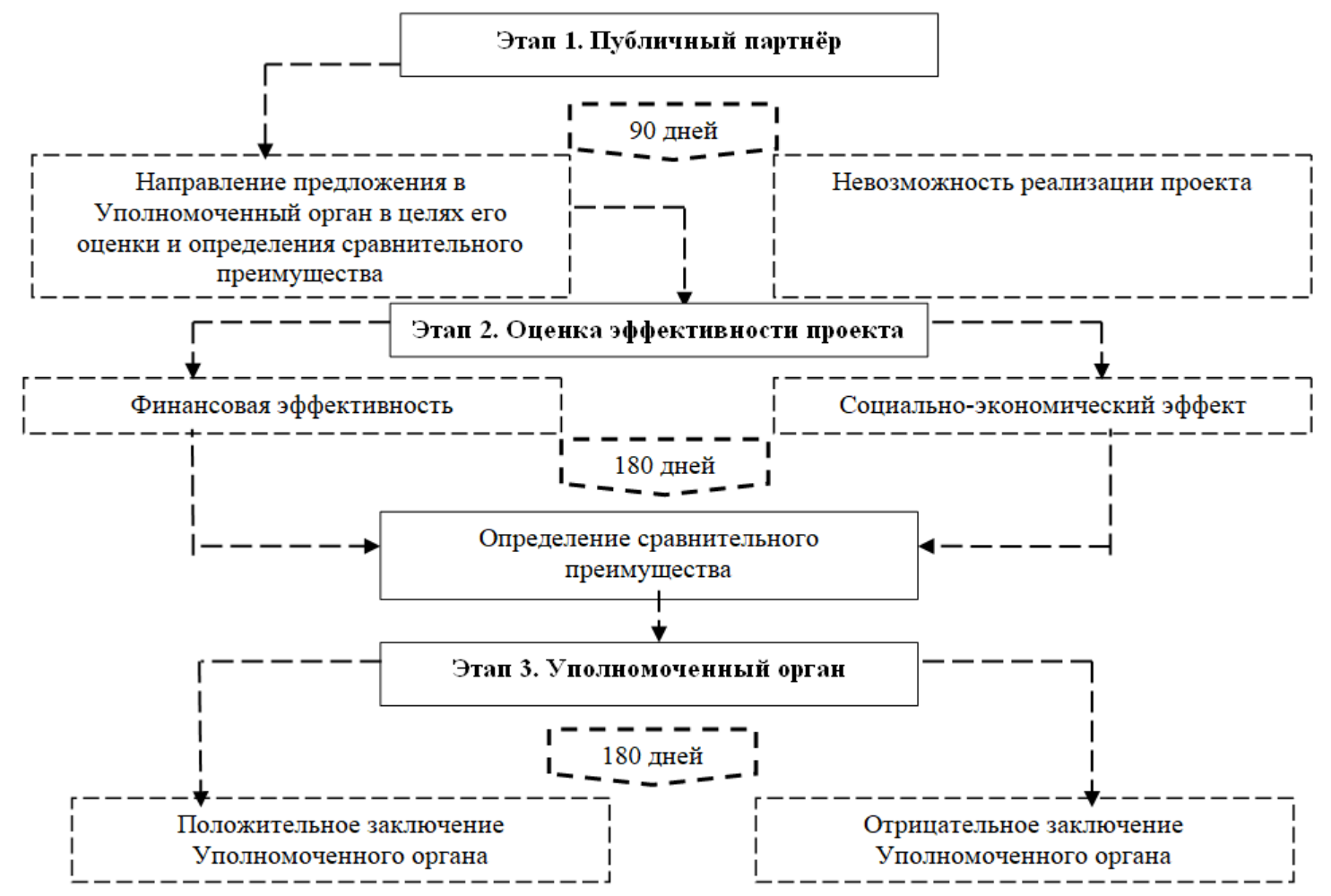

Рис. 2 - Процесс рассмотрения частной инициативы

Проблема 2. Нехватка институциональной инфраструктуры предпринимательства.

Основой деятельности МСП служит материально-техническая база, которая в значительной степени определяет конкурентные преимущества предприятий данного сектора. Малые и средние предприятия испытывают значительную нехватку производственных и офисных помещений. Зачастую приходится пользоваться имуществом крупных компаний с высокими арендными платежами, оказывающими значительное влияние на эффективность бизнеса.

Система МСП характеризуется недостаточно разветвлённой и эфффективной инфраструктурой поддержки государства, а также отсутствием механизма эффрективного международного сотрудничества. Низкая конкурентоспособность отдельных отраслей во многом объясняется высокими затратами производства и дистрибуции готовой продукции в силу неразвитости индрраструктуры бизнес-среды. Наличие собственного производственно-хозяйственного комплекса представляет особый интерес для субъектов МСП, так как долгосрочное присутствие на рынке можно обеспечить только на базе собственных производственно-коммерческих активов. Кроме того, высокие арендные платежи негативным образом влияют на эффеективность бизнеса.

В настоящий момент проблема имущественной базы усугубляется тем, что срок действия преимущественного права выкупа субъектами МСП арендуемого государственного и муниципального имущества согласно Федеральному закону № 159-Ф3 истёк 01.07.2015 г. [5].

Кроме того, максимальный срок рассрочки оплаты при выкупе субъектами МСп арендуемого имущества, равный трём годам, создаёт значительные трудности. Как правило, инвестиции в объекты недвижимости в текущих экономических условиях в лучшем случае могут окупиться через 5-7 лет. Очевидно, что предпринимательский сегмент без сторонней помощи не в состоянии за три года полностью выплатить стоимость выкупаемых у государства объектов. Именно этим и объясняется пассивная роль субъектов МСП в процессе выкупа арендуемого имущества.

Несмотря на наличие принятых государством программ, позволяющих субъектам МСП рассчитывать на некоторые льготные условия пользования услугами естественных монополий и создания собственных объектов инфраструктуры, существует огромное количество административных преград. В частности в 2014 г. Генеральной прокуратурой РФ в ходе проверки исполнения законодательства, регулирующего вопросы подключения объектов к сетям инженерно-технического обеспечения, выявлено 11,5 тыс. нарушений. 
Наиболее распространёнными нарушениями признаны: неправомерное взимание с хозяйствующих субъектов платы за подключение объектов капитального строительства к сетям инженерно-технического обеспечения; неправомерное взимание с хозяйствующих субъектов платы за выдачу технических условий на подключение к сетям инженернотехнического обеспечения; неправомерное сокращение срока действия выдаваемых технических условий ресурсоснабжающими организациями; неправомерный отказ в выдаче технических условий на подключение к сетям инженерно-технического обеспечения.

Государство не принимает никакого участия для снижения расходов МСП, связанных с транспортировкой сырья, материалов и готовой продукции. В данном вопросе крупный бизнес имеет возможность получить экономию на масштабе, что не работает в случае с МСП. Между прочим, большое значение для инфраструктуры предпринимательства играет уровень транспортной развитости региона, в котором осуществляет деятельность конкретный субъект МСП.

Представленные в Табл. 1 данные подтверждают уровень развитости транспорта и связи по федеральным округам России на 01.01.2014 г. Наиболее развиты сети транспорта и связи в Центральном, Северо-Западном, Приволжском и Сибирском федеральных округах. На долю Северо-Западного федерального округа, куда входит Европейский Север России, приходится 19,0\% объёма транспорта и 13,5\% объёма связи России [4].

Таблица 1 - Число организаций транспорта и связи России на 01.01.2014 г.

\begin{tabular}{|l|c|c|c|c|}
\hline \multirow{2}{*}{} & \multicolumn{2}{|c|}{ Транспорт } & \multicolumn{2}{c|}{ Связь } \\
\cline { 2 - 5 } & ед. & $\%$ & ед. & $\%$ \\
\hline Российская Федерация & 163263 & 100 & 14951 & 100 \\
\hline Центральный федеральный округ & 43525 & 26,7 & 5510 & 36,9 \\
\hline Северо-Западный федеральный округ & 31018 & 19,0 & 2018 & 13,5 \\
\hline Южный федеральный округ & 10622 & 6,5 & 893 & 6,0 \\
\hline Северо-Кавказский федеральный округ & 2287 & 1,4 & 466 & 3,1 \\
\hline Приволжский фредеральный округ & 28122 & 17,2 & 2246 & 15,0 \\
\hline Уральский фредеральный округ & 15127 & 9,3 & 1309 & 8,8 \\
\hline Сибирский федеральный округ & 22559 & 13,8 & 1791 & 12,0 \\
\hline Дальневосточный фредеральный округ & 10003 & 6,1 & 718 & 4,8 \\
\hline
\end{tabular}

Однако среди регионов Северо-Западного федерального округа по объёмам действующего транспорта на долю Европейского Севера России приходится всего 15,9\%, по объёмам связи 19\%. Приведённые данные подтверждают низкую степень транспортной развитости регионов Европейского Севера России (Табл. 2).

Таким образом, заявленная гипотеза относительно слабой развитости институциональной инфраструктуры предпринимательства подтверждена наличием административных барьеров по выкупу субъектами МСП арендуемого у государства имущества, преградами в подключении к сетям инженерно-технического обеспечения, а также статистическими данными об уровне развитости транспортной инфраструктуры Европейского Севера России.

Для решения проблем институциональной инфраструктуры, а также слабой вовлечённости субъектов предпринимательства к государственно-частному партнёрству предложим комплекс мероприятий.

Этап 1. Разработка программы комплексного решения отраслевых проблем, учитывающей эффективность точечных программ и способствующей развитию отраслевой инфраструктуры. В частности, реализация мероприятий, повышающих инвестиционную привлекательность отраслей путём создания транспортной логистики, формирование тарифной и налоговой политики государства с учётом возможностей конкретной отрасли, формирование спроса на продукцию и услуги неэффективных отраслей. 
Таблица 2 - Число организаций транспорта и связи Северо-Западного федерального округа России на 01.01.2014 г.

\begin{tabular}{|l|c|c|c|c|}
\hline \multirow{2}{*}{} & \multicolumn{2}{|c|}{ Транспорт } & \multicolumn{2}{c|}{ Связь } \\
\cline { 2 - 5 } & ед. & $\%$ & ед. & $\%$ \\
\hline Северо-Западный федеральный округ & $\mathbf{3 1 0 1 8}$ & $\mathbf{1 0 0}$ & $\mathbf{2 0 1 8}$ & $\mathbf{1 0 0}$ \\
\hline Европейский Север России & $\mathbf{4 9 4 5}$ & $\mathbf{1 5 , 9}$ & $\mathbf{3 7 8}$ & $\mathbf{1 9}$ \\
\hline Республика Карелия & 1114 & 3,6 & 51 & 3 \\
\hline Республика Коми & 780 & 2,5 & 75 & 4 \\
\hline Архангельская область & 1065 & 3,4 & 81 & 4 \\
\hline Вологодская область & 1224 & 3,9 & 92 & 5 \\
\hline Мурманская область & 762 & 2,5 & 79 & 4 \\
\hline
\end{tabular}

Этап 2. Сдача в долгосрочную аренду малым и средним предприятиям части государственной собственности, продаваемой на аукционах. При этом приоритет должен отдаваться региональным предпринимательским структурам, осуществляющим деятельность в аналогичной сфрере (реализация принципов преимущественного права аренды для организаций, профиль которых соответствует допустимым видам предпринимательской деятельности на объекте).

Этап 3. Обеспечение доступа к объектам недвижимости, относящимся к технологической инфраструктуре (электросети, газовая и коммунальная инфраструктура). Предполагает реализацию комплекса мер, направленных на совершенствование законодательства, регулирующего деятельность естественных и локальных монополий. Комплекс мер предполагает стандартизацию административных процедур, установление экономически обоснованных тарифов, вовлечение в коммерческий оборот созданных компаниями объектов технологический инфраструктуры.

Этап 3.1. Внесение изменений в процесс выкупа арендуемого у государства имущества (Федеральный закон № 159-Ф3): продление срока действия преимущественного права выкупа субъектами МСП арендуемого государственного и муниципального имущества до 01.07.2019 г.; увеличение минимального срока рассрочки оплаты при выкупе субъектами МСП арендуемого имущества до 5-7 лет в зависимости от обоснованных предпринимателями сроков окупаемости выкупаемого у государства имущества.

Этап 3.2. Сокращение административных барьеров в сорере подключения объектов к сетям инженерно-технического обеспечения и снижения затрат субъектов МСП: упрощение процесса подключения объектов к системам водоснабжения, водоотведения и теплоснабжения; утверждение единых стандартов и типовых форм договоров на подключение объектов к системам водоснабжения, водоотведения и теплоснабжения; рассрочка оплаты стоимости подключения объектов к системам водоснабжения, водоотведения и теплоснабжения на срок до 18 месяцев; установление упрощённого порядка оформления разрешительных документов на подключение к газораспределительным станциям; утверждение формулы расчёта строительства каждого дополнительного метра (свыше 200 м) для льготных категорий потребителей; предоставление права независимым организациям осуществлять подключение к газораспределительным станциям при одновременной разработке механизма контроля.

Этап 4. Повышение эфффективности государственного предпринимательства за счёт объединения усилий с предпринимательским сектором путём реализации элементов государственно-частного партнёрства. Синергетический эффеект может быть достигнут за счёт объединения опыта субъектов МСП в управлении предпринимательскими процессами и государства в части преодоления административных барьеров. Важно своевременно внести изменения в систему государственного отбора участников ГЧП, так как существующая система предъявляет неоправданно высокие требования к потенциальным участникам государственных проектов.

Этап 5. Выделение кластеров работ в рамках государственного заказа по таким параметрам как сложность работ, требуемый уровень квалификации персонала, наличие опыта выполнения работ, оснащённость техникой и оборудованием. С помощью подобного разделения государственного заказа на работы разных классов можно повысить доступность заказа для МСП, его способность к исполнению отдельных классов 
работ, не требующих уникальных способностей, наличия специального оборудования и опыта.

Этап 6. Пересмотр системы государственного заказа, который в настоящее время содержит неисполнимые предпринимательским сектором требования. Целесообразно в рамках заказа на государственном уровне предусмотреть процесс сотрудничества крупного бизнеса и субъектов МСП. В частности, принимая во внимание низкий уровень оснащённости представителей МСП техникой и оборудованием, слабый опыт выполнения подобных работ, государство должно привлекать МСП в качестве партнёра по исполнителю крупных государственных заказов.

Важно, чтобы условия партнёрства, объём выделяемых МСП работ определялись непосредственно государством во время проведения торгов, чтобы исключить возможности крупного бизнеса по привлечению приближённых субъектов МСП. С помощью подобных способов, несмотря на слабую способность МСП к самостоятельному исполнению государственного заказа, могут быть созданы условия для обеспечения равноправного участия субъектов МСП к государственному (муниципальному) заказу.

Таким образом, на основе выявленных проблем нехватки институциональной инфраструктуры и слабой вовлечённости субъектов МСП к процессу государственночастного партнёрства предложен комплекс мероприятий, направленных на повышение эфффективности функционирования предпринимательского сектора. Основная часть мероприятий предусматривает объединение усилий государства и субъектов МСП для решения существующих проблем.

\section{Список использованных источников}

1. Закон о государственно-частном партнёрстве: руководство по применению. Специальное издание к Международному инвестиционному форуму "Сочи-2015" / Центр развития государственно-частного партнёрства. - М., 2015. - 21 с.

2. Заргарян А.М. Повышение вовлечённости субъектов малого и среднего предпринимательства Европейского Севера России в процесс государственно-частного партнёрства / А.М. Заргарян // Вестник УрФУ. Серия экономика и управление. - 2016. Том 15. - № 6. - С. 889-905.

3. Рейтинг регионов России по уровню развития государственно-частного партнёрства 2014-2015. // Министерство экономического развития России и Центр развития государственно-частного партнёрства при поддержке Торгово-промышленной палаты России. - М., 2015. - 31 с.

4. Транспорт и связь в России. 2014: Стат.сб./Росстат. - М., 2014. - 114 с.

5. Федеральный закон от 22.07.2008 № 159-Ф3 "Об особенностях отчуждения недвижимого имущества, находящегося в государственной собственности субъектов Российской Федерации или в муниципальной собственности и арендуемого субъектами малого и среднего предпринимательства, и о внесении изменений в отдельные законодательные акты Российской Федерации" // Интернет-версия справочно-правовой системы "Консультант Плюс". - URL: http://www.consultant.ru/document/cons_doc_LAW_ $78582 /$.

6. Федеральный закон от 13.07.2015 № 224-Ф3 "О государственно-частном партнёрстве, муниципальном партнёрстве в Российской Федерации и внесении изменений в отдельные законодательные акты Российской Федерации" // Интернетверсия справочно-правовой системы "Консультант Плюс". - URL: http://www.consultant.ru/document/cons_doc_LAW_182660/.

7. Попков В.П. Теоретические основы многофакторного управления развитием современного предпринимательства / В.П. Попков, С.М. Лепёшкин. - СПб: Издательство Политехнического университета, 2011 - 84 с. 